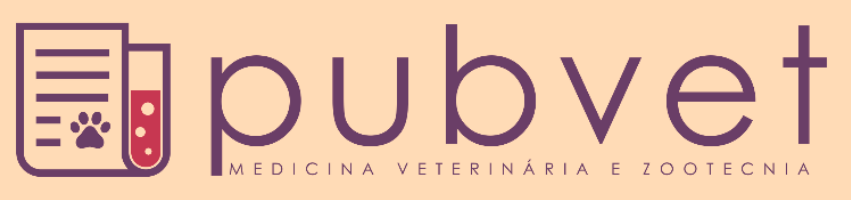

https://doi.org/10.31533/pubvet.v12n12a231.1-8

\title{
Impacto da cisticercose na produção de carnes bovina e suína
}

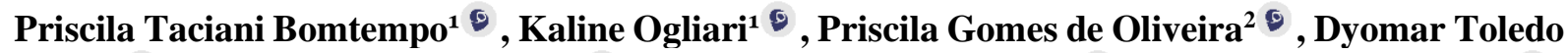

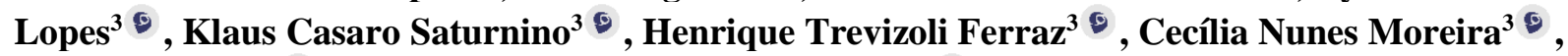 \\ Ísis Assis Braga ${ }^{4}$, Dirceu Guilherme de Souza Ramos ${ }^{3 *} \bullet$
}

${ }^{1}$ Discente do curso de Medicina Veterinária da Universidade Federal de Goiás - Regional Jataí, Departamento de Medicina Veterinária, Jataí, Goiás, Brasil. ${ }^{2}$ Médica Veterinária e Técnica do Laboratório de Análises Clínicas Veterinárias do Hospital Veterinário da Universidade Federal de Goiás - Regional Jataí. ${ }^{3}$ Professor(a) do curso de Medicina Veterinária da Universidade Federal de Goiás - Regional Jataí, Departamento de Medicina Veterinária, Jataí, Goiás, Brasil. ${ }^{4}$ Professora do curso de Medicina Veterinária do Centro Universitário de Mineiros, Mineiros, Goiás, Brasil

*Autor para correspondência E-mail: dgramos_vet@hotmail.com

RESUMO. Cisticercose é uma zoonose de amplo impacto tanto para a saúde animal quanto para a saúde pública. Caracteriza-se pela presença da larva da Taenia solium ou da Taenia saginata, cujos hospedeiros intermediários são suínos e bovinos, respectivamente. $\mathrm{O}$ homem é o hospedeiro definitivo, por alojar a forma adulta do verme, que é a principal fonte de infecção. Em nosso país, a cisticercose na saúde humana e animal gera consequências econômicas, dado o desconhecimento epidemiológico da incidência da zoonose. Por isso faz-se necessário e oportuno medidas de controle do complexo teníasecisticercose, focando parâmetros preliminares de higiene na inspeção sanitária da carne. Dentre outros parâmetros a serem implementados no controle da enfermidade, reprovação de carcaças é uma das principais perdas econômicas em consequência da doença. Objetivou-se, com essa revisão, discorrer acerca da cisticercose e seu impacto na produção de carne bovina e suína no Brasil.

Palavras chave: bovino, cisticerco, saúde pública, suíno, teníase

\section{Impact of cysticercosis on beef and pork production}

ABSTRACT. Cysticercosis is a zoonosis of wide impact for both animal health and public health. It is characterized by the presence of Taenia solium larva or Taenia saginata, whose intermediate hosts are swine and bovine, respectively. Man is the definitive host, for housing the adult form of the worm, which is the main source of infection. In our country, cysticercosis in human and animal health generates economic consequences, given the epidemiological ignorance of the incidence of zoonosis. Therefore, it is necessary and opportune measures of control of the complex teniasis-cysticercosis, focusing on preliminary hygiene parameters in the sanitary inspection of the meat. Among other parameters to be implemented in disease control, carcass reprobation is one of the main economic losses as a consequence of the disease. The objective of this review was to discuss cysticercosis and its impact on beef and pork production in Brazil.

Keywords: bovine, cysticercus, public health, swine, teniasis

\section{Impacto de la cisticercosis en la producción de carne bovina y porcina}

RESUMEN. La cisticercosis es una zoonosis de amplio impacto tanto para la salud animal y la salud pública. Se caracteriza por la presencia de la larva de la Taenia solium o de la Taenia saginata, cuyos hospedadores intermediarios son porcino y bovino, respectivamente. El hombre es el huésped definitivo, por alojar la forma adulta de la tenia, que es la principal fuente de infección. En nuestro país, la cisticercosis en la salud humana 
y animal genera consecuencias económicas, dado el desconocimiento epidemiológico de la incidencia de la zoonosis. Por eso es necesario y oportuno medidas de control del complejo teniasis-cisticercosis, enfocando parámetros preliminares de higiene en la inspección sanitaria de la carne. Entre otros parámetros a ser implementados en el control de la enfermedad, reprobación de canales es una de las principales pérdidas económicas como consecuencia de la enfermedad. Se objetivó, con esa revisión, discurrir acerca de la cisticercosis y su impacto en la producción de carne bovina y porcina en Brasil.

Palabras clave: bovino, cisticerco, salud pública, porcino, teniasis

\section{Introdução}

A carne bovina e suína tem alta relevância para a economia do país, que é um dos maiores exportadores de carnes do mundo, tornando fundamental a adoção de boas práticas na produção (BPP). Estas, por sua vez, consistem na correta gestão da propriedade rural, dos recursos humanos e ambientais; adoção de instalações rurais adequadas, proporcionando manejo correto dos animais no que se refere ao pré-abate; bemestar animal; pastagens; suplementação alimentar; rastreabilidade de processos produtivos e controle sanitário e reprodutivo do rebanho bovino e suíno (Pires 2010; Prado 2010; Anica-Popa 2011).

O complexo teníase $x$ cisticercose é uma doença parasitária de alto potencial zoonótico, sendo o homem, o único hospedeiro definitivo, ou seja, que apresenta a forma adulta do parasita no intestino delgado. No entanto, a maior preocupação com relação à saúde pública é o desenvolvimento da neurocisticercose (NCC), manifestação mais grave, cuja localização dos cisticercos (formas larvais) é no sistema nervoso (Germano \& Germano 2008). De acordo com Neves (2010), o termo cisticercose é identificado pelo ataque aos tecidos musculares do hospedeiro intermediário (suínos e bovinos), ocorrendo pelo consumo de alimentos contaminados com ovos de Taenia solium ou Taenia saginata eliminados pelo hospedeiro definitivo que é o humano.

Já a teníase, segundo Fortes (2004) é a infecção provocada pela forma adulta da $T$. solium ou $T$. saginata no intestino delgado humano que também define a cisticercose como uma infecção gerada pela larva (cisticerco) nos hospedeiros intermediários normais (boi e porco) e, acidentalmente, cães e humanos (especialmente por larvas de T. solium). De acordo Jenkins et al. (2013), a cisticercose bovina e a teníase humana oriunda da $T$. saginata ocorrem de modo hiperendêmico quando em elevada frequência, e igualmente endêmica, em baixa frequência. A enfermidade nos bovinos pode ocorrer de forma epidêmica, ou na forma de surto, devido ao contato entre uma fonte com animais susceptíveis ou decorrentes à aplicação de produtos alimentares contaminados destinados ao gado (WHO 2003). Dutra et al. (2012) mencionaram que a ocorrência da enfermidade no Brasil é variável, estando relacionada, principalmente, com o nível de desenvolvimento da região, o nível de conhecimento da população e as principais atividades agropecuárias desenvolvidas.

Santos et al. (2008) relataram que ovos da $T$. saginata podem sobreviver no ambiente, inclusive na pastagem, durante vários meses, denotando-se a importância dos investimentos em políticas públicas de educação fundamental, educação sanitária e saneamento básico para toda a população, incluindo aos trabalhadores rurais, como cortadores de cana e pessoas que atuam no manejo animal.

Germano \& Germano (2008) afirmaram que a erradicação da T. solium é perfeitamente possível dada as seguintes razões: o ciclo de vida necessita do homem como hospedeiro definitivo; a única fonte de infecção para os hospedeiros intermediários é o homem portador de teníase; os animais domésticos, como hospedeiros intermediários, podem ser controlados; há drogas seguras e eficazes para combater a teníase.

\section{Agente etiológico}

O agente etiológico é a $T$. solium (teníase) ou Cysticercus. cellulosae (cisticercose), tendo o suíno e o homem como hospedeiro intermediário; e T. saginata ou Cysticercus bovis, tendo o bovino como hospedeiro intermediário exclusivo (Couras 2013). Serqueira (2002) mencionou que da família Taenidae, o gênero Taenia é o mais relevante para a saúde humana e medicina veterinária. Neste gênero as principais espécies têm por hospedeiro definitivo o homem ( $T$. solium e T. saginata), cães (Taenia hydatigena e Taenia multiceps) e outras espécies de mamíferos. A importância dos parasitas deste gênero para os animais de produção se deve ao fato de que as larvas desses cestódeos se desenvolvem em tecidos de 
ruminantes e suínos, que atuam como hospedeiros intermediários.

\section{Ciclo Biológico e imunologia}

De acordo com Mahanty \& Garcia (2010), o ciclo de vida da $T$. solium engloba o hospedeiro definitivo, que aloja o verme na fase adulta, e o intermediário, que aloja o cisticerco. Naturalmente, o hospedeiro definitivo (homem) é um consumidor de carne infectada do hospedeiro intermediário (suíno preferencialmente, mas ocorrente em outras espécies, incluindo seres humanos que podem se auto-infectar, agindo também como hospedeiros intermediários), contagiado com ovos do parasita, depositados no meio ambiente via dejetos do hospedeiro definitivo (portador do parasito). Esse ciclo é conhecido como predador-presa que acresce a possiblidade de sobrevivência da população de parasitas por duas subpopulações diferentes quanto à espécie de hospedeiros. Já $T$. saginata possui ciclo similar, entretanto o hospedeiro intermediário é preferencialmente bovino, não ocorrendo na forma larvar em humanos.

Giovannini et al. (2014) descreveu que o ciclo biológico acontece em 4 fases: 1. Os humanos parasitados eliminam as proglotes grávidas cheias de ovos para o exterior. Estas se rompem no meio externo por efeito da contração muscular ou decomposição de suas estruturas. Em alguns casos pode se formar hérnias devido a não cicatrização nas superfícies de ruptura das proglotes, o que facilita a expulsão dos ovos junto às fezes. 2. Um hospedeiro intermediário próprio (suíno ou bovino) ingere os ovos e os embrióforos. No estômago sofrem ação da pepsina que degrada uma substância proteica presente entre os blocos de quitina. No intestino as oncosferas sofrem a ação dos sais biliares, que permitem sua ativação e liberação. As oncosferas liberam-se do embrióforo e movimentam-se no sentido da vilosidade, onde penetram com auxílio dos acúleos. Permanecem nesse local durante cerca de quatro dias para adaptarem-se às condições fisiológicas do novo hospedeiro. Em seguida penetram nas vênulas e atingem as veias e os linfáticos mesentéricos. Através da corrente circulatória são transportados, por via sanguínea, a todos os órgãos e tecidos do organismo até atingirem o local de implantação. Depois atravessam a parede do vaso, instalando-se nos tecidos circunvizinhos. Apesar de se desenvolverem em qualquer tecido mole, as oncosferas preferem os músculos de maior movimentação e oxigenação (masseter, língua, coração) e cérebro. 3. No interior dos tecidos perdem os acúleos e cada oncosfera se transforma num cisticerco que começa a crescer e se mantém viáveis nos músculos por alguns meses ou no cérebro por anos. 4 . O homem adquire o cisticerco ao comer a carne crua ou malcozida. O cisticerco sofre ação do suco gástrico, evagina-se e, através do escólex, se fixa a mucosa do intestino delgado, transformando-se em uma tênia adulta. Três meses após a infecção inicia-se a eliminação das proglotes grávidas. Couras (2013) relatou que na fase inicial de invasão as oncosferas perfuram a parede intestinal e, através dos vasos sanguíneos, disseminam-se por diversos órgãos, com intensa reação inflamatória, resposta imune humoral imediata e ação do complemento por parte do hospedeiro, com grande mortalidade das larvas. As larvas que sobrevivem por mecanismo de escape vão se localizar nos tecidos e evoluem para cisticerco, estimulando uma resposta imune prolongada, tanto humoral, como celular. Em consequência, ocorre a destruição de cisticercos com reação inflamatória e calcificação posterior, principalmente em músculo e tecido celular subcutâneo, menos frequente nas localizações cerebral e ocular, onde permanecem vivos por mais tempo, talvez por resposta imunológica menos intensa. $\mathrm{O}$ autor cita ainda que a resposta imunológica celular de portador de cisticercose vem sendo analisada, mas os estudos ainda são inconclusivos. Cisticerco é capaz de produzir um escape da resposta imune humoral. O componente $\mathrm{C}_{1 q}$ pode ser inibido pela ação da paramiosina; $\mathrm{A}$ taenistatina inibe as vias clássicas e alternativas do complemento parecendo interferir, juntamente com outros fatores na proliferação de linfócitos e com a função dos macrófagos, inibindo a resposta celular. Nos pacientes com neurocisticercose temse notado aumento da concentração das imunoglobulinas IgG, IgM, IgE, IGA e IgD. Côrtes (2000). No entanto, relataram que os ovos são bastante resistentes, principalmente quando envolvidos por uma película de água, com isso podem permanecer nas fezes presente no solo por até um ano, o que facilita sua dispersão em qualquer ambiente. Igualmente resistentes a substâncias químicas, podem ser destruídos por fervura acima de $90^{\circ} \mathrm{C}$. A duração no ambiente é de aproximadamente 12 meses.

Rossi et al. (2014) salientaram que todo o complexo se conclui quando do consumo de carne crua ou malpassada com cisticercos viáveis pelo hospedeiro definitivo. No estômago do ser 
humano a forma larval do parasito sofre ação do suco gástrico e da bile, estimulando a evaginação do escólex que por meio de suas quatro ventosas se fixa na mucosa do intestino delgado e por volta de três meses se torna um parasito adulto.

\section{Taxonomia e morfologia}

Segundo Neves (2010), o parasita é classificado em conformidade com a sua fase evolutiva, ou seja, ovo, larva (cisticerco) e verme adulto. O gérmen da Taenia é uma plântula que prevalece protegida por envoltórios ovulares até o minuto da eclosão no interior do espécime hospedeiro. A composição do ovo pela oncosfera ou gérmen hexacanto, possui três pares de acúleos e uma dupla membrana que reveste e, do lado externo, possui uma casa protetora ou embrióforo, formada por blocos piramidais de quitina que proporciona sustentação às adversidades do meio ambiente. É justamente a partir do embrião hexacanto, após a ingestão do ovo pelo hospedeiro intermediário que se origina a larva ou cisticerco.

Rey (2008) mencionou que os ovos são esféricos, morfologicamente indistinguíveis, medindo cerca de $30 \mathrm{~mm}$ de diâmetro. São constituídos por um revestimento protetor formado por blocos de quitina que proporciona vigor ao meio ambiente. Dentro encontra-se o gérmen hexacanto ou oncosfera, provida de 3 pares de acúleos e dupla membrana (Sousa et al. 2007). Segundo Mahanty \& Garcia (2010), a proteção do gérmen (ovo) dissolve-se com ácido gástrico e enzimas do intestino e o gérmem hexacanto ou oncosfera é despertado, rompendo a membrana protetora e aderindo à mucosa intestinal. Na fase de larva, Silva et al. (2007) expuseram que a cisticercose se caracteriza pelo estágio patológico decorrente da infecção de hospedeiros vertebrados no modo de larva, por intermédio de uma ou mais lesões vesiculares, denominados de cisticerco. O aparecimento de cisticercos na musculatura de carcaças bovinas é vulgarmente chamado de "pipoca", "canjica", "canjiquinha" ou "sagu". Os cisticercos da $T$. solium são constituídos de corpúsculos transparentes com líquido claro, contendo invaginado no núcleo de um escoléx com quatro ventosas, rostelo e colo, enquanto o rostelo é ausente na $T$. saginata. $\mathrm{O}$ cisticerco possui parede composta de três membranas (cuticular ou externa, celular ou intermediária e reticular ou interna). As larvas podem chegar até $12,0 \mathrm{~mm}$ de comprimento depois de quatro meses de infecção (Couras 2013). O tapume dos corpúsculos dos cisticercos é composto de três membranas: cuticular ou externa, celular ou intermediária e reticular ou interna. $\mathrm{O}$ cisticerco que se encontra no sistema nervoso central (SNC) gera a NCC, que é uma doença parasitária. De acordo com Neves (2010), o SNC do homem aloja o cisticerco e o mantem propício por inúmeros anos. Neste período, nota-se inúmeras alterações anatômicas e fisiológicas até a finalização do ciclo larval calcificado. Lopes et al. (2013) mencionaram ainda que as formas vesiculares se tornam translúcidas, ovoides, com até um centímetro de comprimento em torno de 40 dias. Porém, o cisticerco estará maduro totalmente após $60-75$ dias de infecção. A longevidade dos cisticercos varia de meses a anos. Fortes (2004) relatou que a $T$. saginata é um enterro-parasita grande, achatado, em forma de fita, segmentado e de cor branca. Pode medir de 4,0 a 12,0 metros, já tendo sido encontrados exemplares com até 25,0 metros. Possui cabeça (escólex) que serve para fixação, seguidas de pescoço (colo) e estróbilo, formado por proglotes. O escólex geralmente é armado, mas este pode também ser inerme, possui forma quadrangular e não possui rostelo nem ganchos, medindo aproximadamente $1 \mu \mathrm{m}$ de diâmetro. $\mathrm{O}$ estróbilo é formado por numerosas proglótides e as massas testiculares são anteriores aos ovários, ocupando toda a região medular. Morfologicamente similar, a T. solium diferenciase pelo tamanho menor, variando 2,0 a $8,0 \mathrm{~m}$ de comprimento e é composto de escólex, colo e estróbilo. O estróbilo tem a forma de fita que compõe os segmentos proglotes (Couras 2013).

\section{Fatores responsáveis pelas altas taxas de prevalência do complexo Teníase/Cisticercose}

Almeida et al. (2001) explicitaram que os fatores responsáveis pela predominância de altas taxas do complexo teníase $x$ cisticercose em comunidades economicamente menos desenvolvidas são: o sistema de criação de suínos (livres no meio ambiente), hábitos higiênicos e alimentares inadequados (consumo de carne suína não inspecionada, mal passada e contaminação das mãos e outros alimentos), precárias condições de saneamento ambiental, comercialização comunitária de suínos e inexistência de serviços de inspeção da carne. Os autores acrescentaram ainda que o frequente consumo de carne suína e a falta de inspeção da carne comercializada no município podem proporcionar um ambiente favorável ao surgimento do complexo teníasecisticercose. Neste interim, o alto consumo de 
carne suína e bovina sem inspeção, interligada à forma de preparo dos alimentos propiciam a presença de zoonoses. A prevalência do complexo teníase $x$ cisticercose em humanos é pode ser minimizada por medidas sanitária voltada ao abate e comércio de carne suína e de desenvolvimento de hábitos e práticas alimentares adequados.

Almeida et al. (2006) relataram que a cisticercose é o tipo de enfermidade diagnosticada nas carcaças de animais abatidos sob inspeção, gerando perdas econômicas devido à condenação do produto para alimentação humana, limitando as possibilidades de exportação de carne e reduzindo significativamente o prestígio dos produtores no exterior.

\section{Diagnóstico}

O diagnóstico da cisticercose humana é baseado em aspectos clínicos, epidemiológicos, neuroimagem, ligúricos e sorológicos (Togoro et al. 2012). É possível a realização do diagnóstico parasitológico, clínico e imunológico. Nos animais a cisticercose é detectada na inspeção das carcaças, após o abate e a incidência deflagrada diariamente nos abatedouros pelos profissionais do serviço de inspeção sanitária (Gasparetto 2003).

A cisticercose humana pode ser detectada via técnicas sorológicas, radiológicas ou tomográficas computadorizadas, de modo que o diagnóstico da teníase é feito pela identificação de ovos ou proglotes nas fezes ou nas roupas. O diagnóstico específico é de fundamental importância pelo fato de que a cisticercose humana é uma doença extremamente grave e, ao que tudo indica, só é causada pela larva de T. solium (Serqueira 2002).

Segundo Neves (2010), o diagnóstico da cisticercose humana tem como base aspectos clínicos, epidemiológicos e laboratoriais, sendo de grande importância algumas informações sobre o histórico do paciente como procedência, hábitos higiênicos e saneamento básico, procedência de água e alimentos, se costuma consumir carne crua ou malcozida, e investigar se o paciente ou alguém da sua família é ou já foi portador de T. solium. No diagnóstico laboratorial pesquisa-se o parasito, por meio de observações anatomopatológicas de biopsias, necropsias e cirurgias.

Segundo a Organização Mundial da Saúde (WHO 2003), em torno de cinquenta milhões de seres humanos sofrem com epilepsia e 1/3 dos casos ocorre nas regiões de maior incidência da $T$. solium. As regiões acometidas são América
Latina, América do Sul, Sudoeste da Ásia, Africa, dentre outros. Blocher et al. (2011) acrescentaram que nos estados da Bahia, Minas Gerais, São Paulo, Paraná e Santa Catarina a cisticercose é endêmica e provavelmente isso se deve ao fato de haver controle de registros.

\section{Tratamento}

Manhoso \& Prata (2004) mencionaram que não existem drogas eficazes viáveis para a eliminar as cisticercoses a $T$. saginata e $T$. solium em animais, embora sejam capazes de neutralizá-los e mata-los tornando-os em cistos calcicficados. Em humanos, alguns princípios ativos (albendazol, praziquantel, merendazol, niclosamida) podem ser considerados no tratamento e como possível alternativa à cirurgia.

\section{Profilaxia}

Pofilaxia vem do grego "prophylaxis", que é traduzido por "prevenção" e que é composta por três partes distintas: prefixo "pro", que significa "antes"; a palavra "phylax", que é equivalente a "guardião", sufixo "sis", que é adotado para indicar "ação" (Gasparetto 2003).

Fernandes \& Buzetti (2001) apresentaram algumas medidas profiláticas da cisticercose tais como: 1. Esclarecer a população acerca dos riscos e combater a prática do abate clandestino dos bovinos; 2. Garantir a esterilização parasitária das águas residuais nas saídas dos efluentes nas áreas urbanas e o uso de fossas nas áreas rurais; 3. Rastrear os animais abatidos e positivos para cisticercose bovina, com posterior tratamento verticalizado, por parte das autoridades sanitárias.

Ocorrência da cisticercose é um forte indicador de más condições sanitárias dos plantéis, ou seja, com base nos conhecimentos atuais, a erradicação das tênias é perfeitamente possível devido: o ciclo de vida necessitar do homem como hospedeiro definitivo; a única fonte de infecção para os hospedeiros intermediários pode ser controlada; não existe reservatório selvagem significativo; e existem drogas seguras e eficazes para combater a teníase. Providências podem, sem dúvida, resultar em um controle efetivo das contaminações, entretanto, é válido reforçar que os hábitos de higiene devem ser constantemente difundidos entre os trabalhadores rurais e do ramo de alimentos, bem como donas de casa, permitindo que haja uma melhora nas suas condições de trabalho e de vida (Ribeiro et al. 2012). 


\section{Inspeção sanitária}

A efetiva inspeção sanitária da carne nos matadouros é uma atividade preventiva de importância para a saúde pública, afastando do mercado carnes imprópria para consumo humano. A prevenção da teníase humana é vital por meio da destinação adequada de carcaças e órgãos de bovinos parasitados (Monteiro et al. 2006).

Moreira et al. (2002) argumentaram ainda que no Brasil a inspeção em matadouros é efetivada principalmente nas grandes cidades. Vale ressaltar que na maioria dos municípios os animais são abatidos e comercializados sem fiscalização sanitária, de modo que carcaças parasitadas com cisticercose não são identificadas, colocando em risco os consumidores finais da carne $\mathrm{e}$ contribuindo com a disseminação da zoonose. Calil (2011) relataram que o serviço de inspeção federal fiscaliza em torno de $49 \%$ dos animais abatidos no Brasil.

\section{Impactos da cisticercose na produção de carne bovina e suína}

Neves (2010) expõe que a redução da cisticercose de forma impactante consiste no tratamento de pessoas acometidas pela teníase, dado ao fato de que o homem é o hospedeiro definitivo e que contribui substancialmente com a disseminação de doenças tanto nos rebanhos bovinos como suínos.

Acevedo-Nieto et al. (2012) consideram que a cisticercose humana e animal geram um problema de caráter socioeconômico e de saúde pública. Em que a zoonose na atualidade é endêmica em inúmeros países em desenvolvimento, principalmente nas áreas rurais.

Neves (2010) expõe que o grande impacto em termos de declínio da cisticercose, é o tratamento das pessoas acometidas com teníase (solitária), pois o homem sendo o único hospedeiro definitivo é o que contribui para a disseminação da doença nos rebanhos bovinos. Caracterizando, possivelmente a população acometida com solitária obteve um esclarecimento melhor a respeito do complexo teníase $x$ cisticercose, principalmente em termos de tratamento, o que poderia ajudar a explicar a queda notada a partir de 2010.

As carcaças de bovinos contendo cisticercose serão condenadas quando apresentarem infestação intensa (comprovação de um ou mais cistos em incisões praticadas em várias partes de musculatura e numa área correspondente a aproximadamente à palma da mão). A rejeição parcial será adotada nos seguintes casos: 1quando se verifique infestação discreta ou moderada, após cuidadoso exame sobre o coração, músculos da mastigação, língua, diafragma e seus pilares, bem como, sobre músculos facilmente acessíveis. Nestes casos devem ser removidas e condenadas todas as partes com cistos, inclusive os tecidos circunvizinhos; as carcaças são recolhidas às câmaras frigoríficas ou desossadas e a carne tratada por salmora, pelo prazo mínimo de 21 (vinte e um) dias em condições que permitam, a qualquer momento, sua identificação e reconhecimento. Esse período pode ser reduzido para 10 (dez) dias, desde que a temperatura nas câmaras frigoríficas seja mantida sem oscilação e no máximo a $1^{\circ} \mathrm{C}$ (um grau centígrado); 2- quando o número de cistos for maior do que o mencionado no item anterior, mas a infestação não alcance generalização, senso a carcaça destinada à esterilização pelo calor; 3 - podem ser aproveitadas para consumo as carcaças que apresentem um único cisto já calcificado, após remoção e condenação dessa parte (Brasil, 2017). Tratando da carne de suínos é permitido o aproveitamento de tecidos adiposos procedentes de carcaças com infestações intensas por "Cysticercus cellulosae", para o fabrico de banha, rejeitando-se as demais partes do animal (Brasil, 2017).

Fernandes \& Buzetti (2001) informam que o rebanho brasileiro se encontra em circunstancia de alerta quanto as possibilidades de exportação de carnes, dado ao fato da redução do prestigio dos produtos ofertado ao mercado exterior. Alerta ainda acerca da reflexão em torno da pecuária brasileira, limitando as possibilidades de exportação de carnes, diminuindo o prestígio dos países produtores e o valor de seus produtos dado fator produto inadequado.

\section{Referências bibliográficas}

Acevedo-Nieto E.C., Ferreira P.S., Santos T.O., Peixoto R.P.M.G., Silva T.O., Fellipe A.G., A. P.P.S. \& Caldi J.F.B. 2012. Prevalência do complexo teníase-cisticercose na zona rural de Matias Barbosa, MG. Semina: Ciências Agrárias 33, 2307-2314.

Almeida L.P., Franceschini S.C.C., Priore S.E., Ribeiro S.M.R. \& Castro L.C.V. 2001) Fatores predisponentes à ocorrência do complexo teníase-cisticercose, em município do sudeste do Brasil. Higiene Alimentar 15, 34-38. 
Almeida S.M., Reis D.O., Moreira M.D. \& Palmeira S.B.S. 2006. Cisticercos em bovinos procedentes de minas gerais e abatidos em frigoríficos. Higiene Alimentar 20, 40-43.

Anica-Popa I. 2011. Measuring food safety on the extended food supply chain. Management \& Marketing 6, 139.

Blocher J., Schmutzhard E. \& Wilkins P.P. 2011. A cross-sectional study of people with epilepsy and neurocysticercosis in Tanzania: clinical characteristics and diagnostic approaches. PLoS Negl Trop Dis 5, 1185.

Calil R.M. 2011. Segurança dos Alimentos - A produção de carne. Revista Nacional da Carne $411,102$.

Côrtes J.A. 2000. Complexo teníase humanaCisticercose bovina e suína II-Cisticercose bovina e suína. Revista de Educação Continuada em Medicina Veterinária e Zootecnia do CRMV-SP 3, 61-71.

Couras J.R. 2013. Dinâmica das doenças infecciosas e parasitárias. Guanabara Koogan, Rio de Janeiro, Brasil.

Dutra L.H., Girotto A., Vieira R.F.C., Vieira T.S.W.J., Zangirolamo A.F., Marquês F.A.C., Headley S.A. \& Vidotto O. 2012. The prevalence and spatial epidemiology of cysticercosis in slaughtered cattle from Brazil. Semina: Ciências Agrárias 33, 1887-1896.

Fernandes J.O.M. \& Buzetti W.A.S. 2001. Prevalência de cisticercose em suínos abatidos em frigoríficos sob inspeção federal, da $9^{\mathrm{a}}$ Região Administrativa de Araçatuba. Higiene Alimentar 15, 30-37.

Fortes E. 2004. Parasitologia veterinária. Editora ícone, São Paulo.

Gasparetto A.L. 2003. Prevalências de Fasciolose e Cisticercose encontradas nos abates do Frigorífico. UTP, Curitiba, Paraná, Brasil.

Germano L.M.P. \& Germano S.I.M. 2008. Higiene e vigilância sanitária de alimentos. Manole, São Paulo, Brasil.

Giovannini C.I., Carvalho T.S., Cabral J.F., Brasil R.B. \& Santos P.A. 2014. Aspectos econômicos e epidemiológicos da cisticercose bovina-revisão de literatura. Revista Eletrônica Interdisciplinar 2, 6-12.

Jenkins D.J., Brown G.K. \& Traub R.J. 2013. 'Cysticercosis storm'in feedlot cattle in northwest $\mathrm{N}$ ew $\mathrm{S}$ outh $\mathrm{W}$ ales. Australian veterinary journal 91, 89-93.

Lopes W.D.Z., Cruz B.C., Soares V.E., Nunes J.L.N., Teixeira W.F.P., Maciel W.G., Buzzulini C., Pereira J.C.M., Felippelli G., Socol V.T., Oliveira G.P.d. \& Costa A.J.d.
2013. Historic of therapeutic efficacy of albendazol sulphoxide administered in different routes, dosages and treatment schemes, against Taenia saginata cysticercus in cattle experimentally infected. Experimental parasitology.

Mahanty S. \& Garcia H.H. 2010. Cysticercosis and neurocysticercosis as pathogens affecting the nervous system. Progress in neurobiology 91, 172-184.

Manhoso F.F.R. \& Prata L.F. 2004. Prevalência de cisticercose bovina na Região Oeste do estado de São Paulo. Higiene Alimentar 18, 42-49.

Monteiro L.L., Pinto P.S.A. \& Dias F.S. 2006. Evaluation of the ELISA test for the antibody detection in cattle naturally and experimentally infected with Cysticerccus bovis. Veterinary parasitology 141, 260-263.

Moreira M.D., Almeida L.P., Reis D.O. \& Santos W.L.M. 2002. Cisticercose bovina: um estudo com bovinos abatidos em matadouro municipal de Uberlândia, MG. Higiene Alimentar 16, 3741.

Neves D.P. 2010. Parasitologia Humana. Atheneu, Belo Horizonte, Minas Gerais, Brasil.

Pires A.V. 2010. Bovinocultura de Corte. FEALQ, Piracicaba, São Paulo.

Prado I.N. 2010. Produção de bovinos de corte e qualidade da carne. Eduem, Maringá, Paraná, Brasil.

Rey L. 2008. Parasitologia - Parasitos e doenças parasitárias do homem nos trópicos ocidentais. Guanabara: Koogan, Rio de Janeiro, Brasil.

Ribeiro N.A.S., Telles E.O. \& Balian S.C. 2012. O complexo teníase humana-cisticercose: ainda um sério problema de saúde pública. Revista de Educação Continuada em Medicina Veterinária e Zootecnia do CRMV-SP 10, 2025.

Rossi G.A.M., Grisolio R., Paula A., Prata L.F., Buerger K.P. \& Lux Hoppe E.G. 2014. Situação da cisticercose bovina no Brasil. Semina-ciencias Agrarias 35, 927-938.

Santos V.C.R., Ramos E.T.R., Almeida Filho F.S., Pinto J.M.S. \& Munhoz A.D. 2008. Prevalência da cisticercose em bovinos abatidos sob inspeção federal do município de Jequié, Bahia, Brasil. Ciência Animal Brasileira 9, 132-140.

Serqueira T.C. 2002. Parasitologia Animal, Animais de Produção. EPUB, Rio de Janeiro, Brasil. 
Silva M.C., Cortez A.A., Aquino-Cortez A., Valente M. \& Toniolli R. 2007. Cisticercose suína, teníase e neurocisticercose humana no município de Barbalha, Ceará Porcine cysticercosis, taeniasis and human neurocysticercosis in municipal district of Barbalha, Ceará. Arquivo Brasileiro de Medicina Veterinária e Zootecnia 59, 371-375.

Sousa W.K., Pessoa S.M.C., Minozzo J.C. \& Thomaz S.V. 2007. Prevalência da cisticercose bovina do Brasil: avaliação de 26.465 bovinos inspecionados no SIF 1710. Paraná: Ciências Agrárias 28, 675-684.

Togoro S.Y., Souza E.M. \& Sato N.S. 2012. Diagnóstico laboratorial da neurocisticercose: revisão e perspectivas. Jornal Brasileiro de
Patologia e Medicina Laboratorial 48, 345355.

WHO 2003. World Health Organization. Diet, nutrition and the prevention of chronic diseases. Report of a joint WHO/FAO expert consultation. WHO technical report series 916.

Recebido: 17 outubro, 2018

Aprovado: 9 novembro, 2018

Publicado: 27 dezembro, 2018.

Licenciamento: Este artigo é publicado na modalidade Acesso Aberto sob a licença Creative Commons Atribuição 4.0 (CC-BY 4.0), a qual permite uso irrestrito, distribuição, reprodução em qualquer meio, desde que o autor e a fonte sejam devidamente creditados. 